\title{
Status-dependent and strategic growth adjustments in female cooperative cichlids
}

\author{
Dik Heg
}

Received: 11 September 2009 /Revised: 3 February 2010 /Accepted: 24 February 2010/Published online: 23 March 2010

(C) Springer-Verlag 2010

\begin{abstract}
Male group-living cichlids show status and strategic adjustments in growth, but females appear not to show these growth adjustments. Here, an experimental study in the Lake Tanganyika cichlid Neolamprologus pulcher elaborates on these findings. Females did not show status-dependent growth: (1) Growth in females decelerated with body size but did not depend on social status (breeder or helper), and (2) female helpers did not increase their growth rate after becoming a breeder. Females showed limited evidence for strategic growth: (3) Female helpers did not significantly adjust their growth rate depending on the treatments (comparing female helpers living in groups with a small or a large breeder female); but within the small breeder female treatment, helper growth was significantly related to their body size difference (breeder size-helper size), suggesting a strong non-linear effect of size differences on female helper growth. I conclude that these female cichlids show no status-dependent growth and only strategic growth adjustments when the size difference between the helper female and her breeder female is particularly small.
\end{abstract}

Keywords Reproductive competition - Cooperative breeding - Dominance - Body size - Growth rate .

Status-dependent growth $\cdot$ Strategic growth $\cdot$ Cichlidae

Communicated by J. Krause

D. Heg $(\bowtie)$

Department of Behavioural Ecology,

Institute of Ecology and Evolution, University of Bern,

Wohlenstrasse 50a,

CH-3032 Hinterkappelen, Switzerland

e-mail: dik.heg@iee.unibe.ch

\section{Introduction}

Group-living fish show distinct size hierarchies, where the largest fish of each sex dominates all other group members and usually take the largest share of reproduction (e.g. Fricke and Fricke 1977; Buston 2003; Heg and Bachar 2006; Heg et al. 2005a, b; Kohler 1998; Awata et al. 2005; Dierkes et al. 2008). Subordinate group members are either tolerated as 'helpers' in the group (i.e. help in brood care, territory defence and maintenance, Taborsky and Limberger 1981) or tolerated but do not show help (Buston 2004; Mitchell 2003). Since these size hierarchies are so ubiquitous in group-living fish and may also apply to territorial fish in general (Kohda et al. 2008), they need an explanation.

Evidence has accumulated that the threat of eviction by larger-sized dominant individuals may play a role in subordinate growth regulation (Buston 2003; Heg et al. 2004b; Wong et al. 2007). As argued by Heg et al. (2004b), this effect may come about by top-down regulation (e.g. dominants despotically exclude subordinates from preferred feeding sites, Whiteman and Cote 2004; but see also Harwood et al. 2003; Sloman et al. 2000) or by bottomup regulation (e.g. subordinates voluntarily reduce their food intake and growth rate accordingly to avoid eviction, Wong et al. 2007, 2008). In any case, reduced growth is likely to affect fitness in fish (e.g. female body size correlates with egg production: Heg and Hamilton 2008; male body size correlates with gonad mass and paternity success: Awata et al. 2006; Heg et al. 2006, 2008), even though individuals may show catch-up growth compensating for some of the losses in early life (Royle et al. 2005; Metcalfe and Monaghan 2003; Hofmann et al. 1999; Ali et al. 2003; but see Francis 1988), so the fitness loss is 
expected to persist until the moment they have completely compensated their initial reduced growth.

In the cichlid Neolamprologus pulcher subordinates are on average helpful to the dominants (Brouwer et al. 2005; Heg et al. 2005b, therefore, henceforth called 'helpers'), and dominants (so called 'breeders') take the largest share of reproduction (Heg et al. 2006; Heg 2008). Male helpers that are closely size-matched to new immigrant breeder males are evicted (Balshine-Earn et al. 1998). Helper males reduce their growth rate when living in groups with small breeder males ('strategic growth', Heg et al. 2004b), and third ranking males increase their growth rate when the second ranking male is removed (Hamilton and Heg 2008). Breeder males also show a higher growth rate than helper males ('statusdependent growth', Taborsky 1984; Bergmüller et al. 2005; Heg et al. 2004b; Hamilton and Heg 2008). Growth adjustments in females are less clear. Laboratory reared groups do not show distinct size hierarchies amongst females, and third ranking females do not increase their growth rate upon removal of the second ranking individual, in contrast to the hierarchies and growth adjustments males show (Hamilton and Heg 2008). However, there are some notable differences between males and females, which might explain differences in their social regulation of growth. Firstly, males and females show different hormonal titres and neurological profiles (Aubin-Horth et al. 2007; Buchner et al. 2004; Bender et al. 2006; Desjardins et al. 2006, 2008b). Secondly, helper males (Fitzpatrick et al. 2006; Heg et al. 2006) seem more reproductively suppressed than helper females (AubinHorth et al. 2007; Heg and Hamilton 2008; Heg 2008), and the level of subordinate paternity depends on the number of same-sex subordinates in the group and their sizes (Heg et al. 2008). Thirdly, females may mate polygynously with the dominant male (Limberger 1983; Desjardins et al. 2008a), in which smaller group member females are more successful if they are closely sizematched with the largest, dominant female group member (Heg and Hamilton 2008). Fourthly, female subordinates do not impose direct fitness costs on the dominant female (Heg and Hamilton 2008; Heg et al. 2008), except for a reduction in the dominant female's growth (Heg and Hamilton 2008), and may be helpful due to alloparental brood care provided to the dominant female (Heg et al. 2009). Since both subordinate male and subordinate female parentage increases with their body size (Heg 2008; Heg et al. 2006, 2008), all subordinates will be selected to grow as fast as possible. However, since male subordinates impose direct reproductive costs on the dominant male and female subordinates do not impose such costs on the dominant female, I hypothesise that dominant males have more to gain from suppressing male subordinate reproductive participation by a reduction in male subordinate growth (either by top-down or bottom-up regulation through the threat of eviction), than dominant females have from suppressing female subordinate reproduction through changes in female subordinate growth. Therefore, I expected females to show no or weaker growth adjustments than males do.

Here, I test formally whether female $N$. pulcher show status-dependent and strategic growth, following the experimental procedure of Heg et al. (2004b). If females show status-dependent growth, breeder females should grow faster than helper females of the same initial size. Moreover, if the breeder female is removed from the group, helper females gaining the dominant position should increase their growth rate compared to control females. Alternatively, breeder females may fail to show a higher growth rate compared to helper females because they tailor their growth to the size difference with the breeder male (see also Munday et al. 2006; Awata and Kohda 2004). If females show strategic growth, helper females living with a relatively large breeder female should increase their growth compared to helper females living with a relatively small breeder female.

\section{Materials and methods}

\section{Experimental setup}

I created artificial groups of four unrelated individuals from laboratory-reared fish living in non-breeding aggregations before the experiment. These were descendants from $N$. pulcher caught at the southern end of Lake Tanganyika in 1996 (near Mpulungu, Zambia). I created eight sets consisting of four groups and a single control pair $(n=8 \times$ $5=40$ groups). Groups were maintained in adjacent 125-1 compartments within one 1,000-1 aquarium. Compartments were separated by alternating clear and opaque partitions, such that each group could see one adjacent group. Compartments measured $65 \mathrm{~cm}$ length $\times 32.5 \mathrm{~cm}$ breadth $\times 65 \mathrm{~cm}$ height. The floor of the aquarium was covered with a layer of sand (ca. $6 \mathrm{~cm}$ ). Each compartment contained: two clay flower pot halves (used as shelters and for breeding), two translucent tubes (suspended near the surface, used as a refuge from aggression), and a suspended filter (also used as a refuge). The availability of refugia ensured that helpers could always avoid interactions with the breeders, who usually stayed near the pot halves. The clear partitions to the neighbouring group ensured that helpers could assist the breeders in territory defence, which may promote group cohesion (D. Heg personal observations). The treatments (see below) of neighbouring groups were randomised.

I measured the sizes of the fish at the start of the experiment (body mass in milligram and standard length 
(SL) in $0.5-\mathrm{mm}$ accuracy), sexed them by examining the genital papilla, and marked all fish individually (by taking a small fin-clip from the dorsal and/or anal fin). Marking had no adverse effects on the fish. All groups contained a breeding male, a large helper female and a small helper female who remained in their group throughout all sequences of the experiment (sequence 1 to 3, Fig. 1a, see below). Each set contained two groups with a small breeding female and two groups with a large breeding female (Fig. 1b). At the end of sequence 1 (30 days), all fish were again measured, and the breeding females in each group were all replaced with another breeding female in a full factorial design (start of sequence 2, duration also 30 days, Fig. 1b). This is the same design as used in Heg et al. (2004a) with males, except that a third sequence was added (see below). The female dominance rank within groups was quickly decided based on the body sizes of fish, with the breeding female taking rank 1, large helper female rank 2, and small helper female rank 3 . After sequence 2 (30 days), all fish were measured again, and the breeding female in each group was removed and replaced with a very
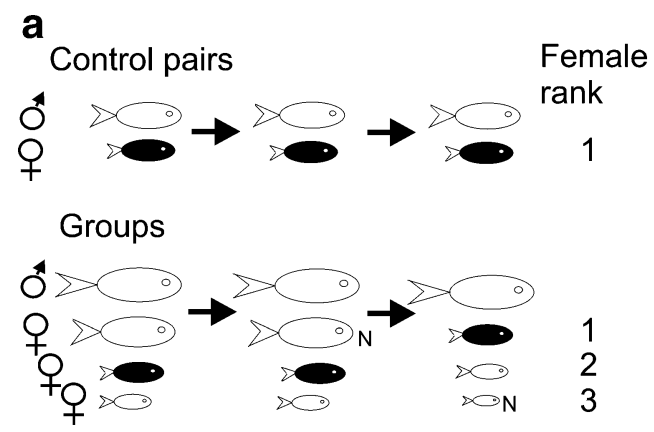

b

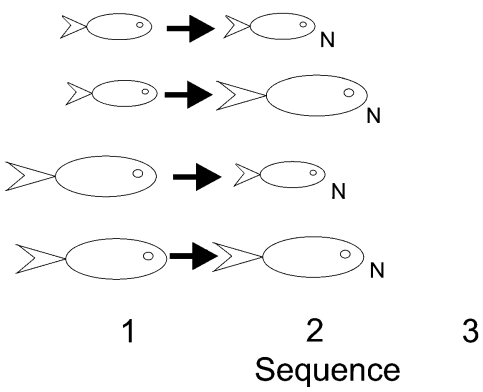

Treatment

ss

SL

LS

LL
Fig. 1 Design of the experiment. a In control pairs, focal females (black) were breeding with a male throughout all three sequences. In groups, focal females (black) and small females were with a breeder female and male in the first sequence (for 30 days) and the second sequence (for 30 days). Note that breeder females were exchanged in between (indicated with $N$ ). After the second sequence, all breeder females were permanently removed, and a very small helper female was added (indicated with $N$ ), and this third sequence lasted another 30 days. Note that this removal resulted in changes of female rank, and all focal females were now the dominant female in their group. b Shows in detail how the sizes of the breeder females were changed in a two-way factorial design from sequence 1 to 2 small helper female (sequence 3, Fig. 1a). Now the large helper female gained the breeding female rank, the small helper female became large helper female and the very small helper female was the smallest group member. Sequence 3 lasted another 30 days.

Control pairs contained a breeding female throughout all three sequences and were not replaced, and these females had only a breeding male available inside their compartment (Fig. 1a) and were of similar initial size as the large helper females. Note that breeder males were larger than the females in all groups and pairs at the start of the experiment and thus were dominant over all females.

At the start of the experiment, the following body sizes were used (mean SL $\mathrm{mm} \pm \mathrm{SD}$ ). Control pairs $(n=8)$, breeder males $51.9 \pm 5.2$, breeder females $47.0 \pm 4.5$; groups, breeder males $73.1 \pm 6.2(n=32)$, small breeder females $52.9 \pm$ $4.6(n=16)$ or large breeder females $69.3 \pm 2.8(n=16)$, large helper females $46.3 \pm 5.4(n=32)$, small helper females $36.9 \pm$ $6.1(n=32)$. During sequence 3, very small helper females $(31.2 \pm 5.3 \mathrm{~mm} \mathrm{SL}, n=32)$ were added. In total, 18 fish had to be replaced by a similarly sized fish because they were no longer accepted inside their groups, and this was accounted for by adding an individual identity effect in all models (three breeder males; three breeder females, six large helpers and six small helpers).

After the body measurements, the two smallest females were released directly into their respective compartments. The male and the largest female were kept overnight in single isolation nets within their compartments before being released. Water temperature was maintained at an average of $28.0 \pm 0.7 \mathrm{SD}^{\circ} \mathrm{C}$. The light regime was a $13: 11 \mathrm{~h}$ light/ dark cycle. Groups were fed daily with commercial TetraMin flake food ad libitum, supplemented with fresh food (Artemia spp., Daphnia spp., mosquito larvae) during 2 days/week.

\section{Statistical analyses}

Results were corrected for individual identity effects (repeated measures) using Generalised Estimating Equations (GEE) in SPSS 15 (Norusis 2007). Focal female growth was related to the covariate $\operatorname{Ln}$ [initial size] and $\operatorname{Ln}$ [initial size difference with breeder female], where initial size is SL or body mass, to account for diminishing growth with size and diminishing effects with a diminishing size difference. Female breeder growth was linearly related to initial size and growth, and some large females overtook the males in size during the two sequences. Therefore, female breeder growth was corrected for initial size and ln-transformation was not possible, again using GEE.

If females show status-dependent growth: (1) Breeder females (control pairs) should grow faster than similar sized large helper females (groups, using data from sequence 1 
and 2), and (2) large helper females should increase their growth rate after attaining the breeder position (groups, comparing growth during sequence 2 as a helper vs growth during sequence 3 as a breeder of the same individual females). I considered this the most important test of the status-dependent growth hypothesis and therefore also present effect sizes $d$ and 95\% confidence intervals CI (formula 4 and 15 from Nakagawa and Cuthill 2007). If females show strategic growth, large helper females should adjust their growth rate to the size difference with their breeder female group member (groups, using data from sequence 1 and 2).

\section{Results}

Status-dependent growth was tested in two ways. First, the growth of control females was compared to the growth of large helper females, during sequence 1 and 2. Growth in all females decelerated with body size but did not depend on social status (Fig. 2a, b, Table 1). If anything, large
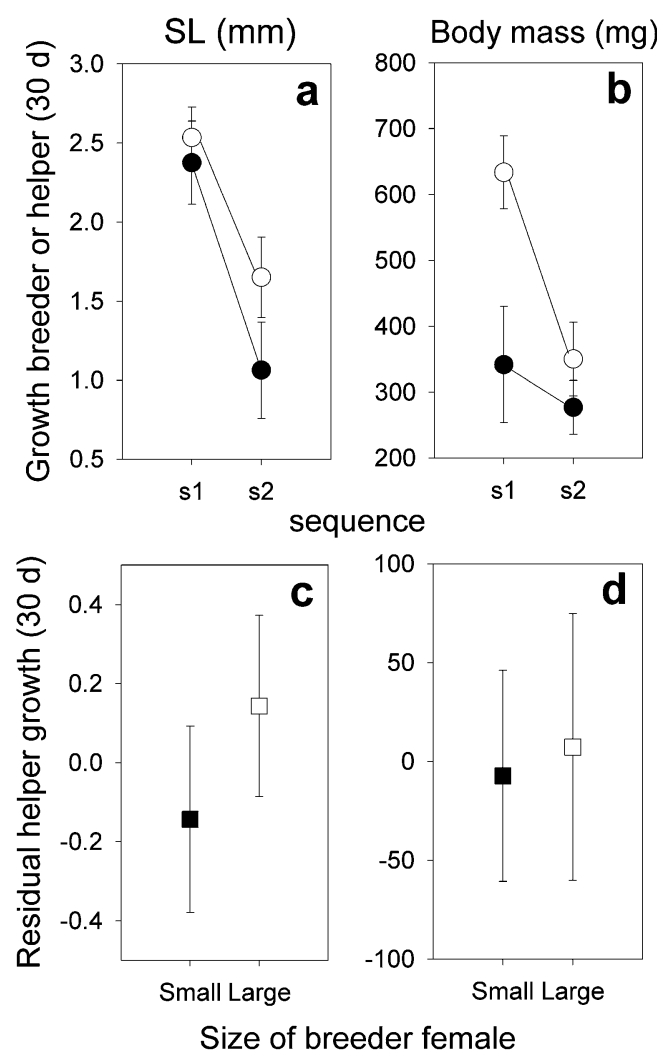

Fig. 2 a, b Status-dependent growth rate of females (black dots breeder females living in pairs $n=8$ each dot), white dots large helper females living in groups $n=16$ each dot). c, d Strategic growth of large helper females: helper growth depending on the treatments, i.e. the size of the dominant breeder female in their group (black square small breeder female $n=32$, white square: large breeder female $n=32$ ). Depicted are means with SEM helper females were growing faster during the first sequence compared to breeder females in body mass, as indicated by the significant interaction (Fig. 2b, Table 1). Note that the reduction in growth in all females over time (sequence 1 to 2 ) is due to cichlids decelerating growth with increasing body size. Second, large female helpers did not increase their growth rate after becoming breeder (Fig. 3, paired $t$ tests growth sequence 2 vs 3, $n=27$; growth SL: $t=0.36, P=0.72$; growth mass: $t=-0.04, P=$ 0.97). Effect sizes $d$ (with $95 \% \mathrm{CI}$ ) for SL and mass were 0.105 ( -0.467 to 0.677$)$ and $-0.012(-0.577$ to 0.554$)$, respectively. To control for sequence effects, change in growth of these large helpers was also compared to change in growth of control pair breeder females (growth change= growth[sequence 3] minus growth[sequence 2], Fig. 3), but again, there were no significant effects (ANOVAs on growth change, former large helper females vs control females: SL growth change: $F_{1,34}=0.07, P=0.79$; mass growth change: $F_{1,34}=0.66, P=0.42$ ).

Strategic growth of large female helpers was tested by comparing their growth depending on the initial body size difference with their breeder female at the start of sequence 1 and 2. Helper growth did not depend on this size difference (Fig. 2c, d, Table 2). However, there was evidence for a nonlinear effect of the difference in size between the breeder female and large helper female on large helper female growth (Fig. 4), with large helper females showing decreased growth only when the size difference was very small. If the growth rate of large helper females was analysed for the small breeder female treatment only, there was a significant positive effect of the size difference on their growth rate (ANOVA, $n=32$, effect of size difference: $F_{1}=.25, P=0.029$, coefficient \pm SE: $0.27 \pm 0.12$; corrected for random effect of sequence: $F_{1}=$ 5.90, $P=0.022$ ).

Large and small breeder females were living with a large breeder male in all groups. The initial size difference with their breeder male varied accordingly between -0.5 and $30.0 \mathrm{~mm}$ or $-1,017$ and $11,083 \mathrm{mg}(n=32$, breeder malebreeder female size or mass). Nevertheless, this size difference did not influence their growth rate (GEEs: growth SL $P=0.46$; growth mass $P=0.24$ ) but solely depended on female breeder initial size (effect of SL $P=$ 0.002 ; effect of mass $P<0.001$, respectively; all cases $n=$ $32 \times 2$ sequences $=64$, corrected for individual and sequence effects, data sequence 1 and 2).

\section{Discussion}

Females in the cichlid $N$. pulcher appeared not to show status-dependent growth (in contrast to the males: Heg et al. 2004b) and only showed strategic growth adjustments when 
Table 1 GEE statistical analysis of status-dependent growth in female cichlids

\begin{tabular}{|c|c|c|c|c|c|c|}
\hline \multirow[t]{2}{*}{ Parameter } & \multicolumn{3}{|c|}{ Growth SL (mm, $n=80)$} & \multicolumn{3}{|c|}{ Growth body mass (mg, $n=80$ ) } \\
\hline & $\chi^{2}$ & $d f$ & $P$ & $\chi^{2}$ & $d f$ & $P$ \\
\hline Intercept & 42.6 & 1 & $<0.001$ & 15.2 & 1 & $<0.001$ \\
\hline Status & 1.6 & 1 & 0.2 & 0.002 & 1 & 0.96 \\
\hline Initial size $^{\mathrm{a}}$ & 14.2 & 1 & $<0.001$ & 0.9 & 1 & 0.34 \\
\hline Sequence & 14.3 & 1 & $<0.001$ & 13.2 & 1 & $<0.001$ \\
\hline Status $\times$ initial size & 2.0 & 1 & 0.16 & 1.1 & 1 & 0.29 \\
\hline Status $\times$ sequence & 0.4 & 1 & 0.53 & 5.9 & 1 & 0.015 \\
\hline
\end{tabular}

Data comparing large helper females $(n=32 \times 2$ sequences $)$ and control breeder females $(n=8 \times 2$ sequences $)$ in sequence 1 and 2 . Results corrected for random individual effects

$S L$ standard length

${ }^{a}$ Focal size as the start of the sequence, SL for growth SL and body mass for growth mass

the size difference with their breeder female was very small. Therefore, contrary to expectation, there was no effect of the treatments (small or large breeder female) on large helper female growth, which appeared due to a threshold effect of the size difference between the breeder female and the large helper female on helper female growth: below a 6-mm size difference, helper female growth was substantially reduced, whereas above a 6-mm difference helper female growth was not affected. The relatively fast growth of the helper females compared to the breeder females complements the findings of Heg and Hamilton (2008). They found that unrelated subordinate females try to reproduce inside groups, this being more likely when they have a small size difference with the breeder female. Below a size difference threshold of ca. $6 \mathrm{~mm}$, subordinate females

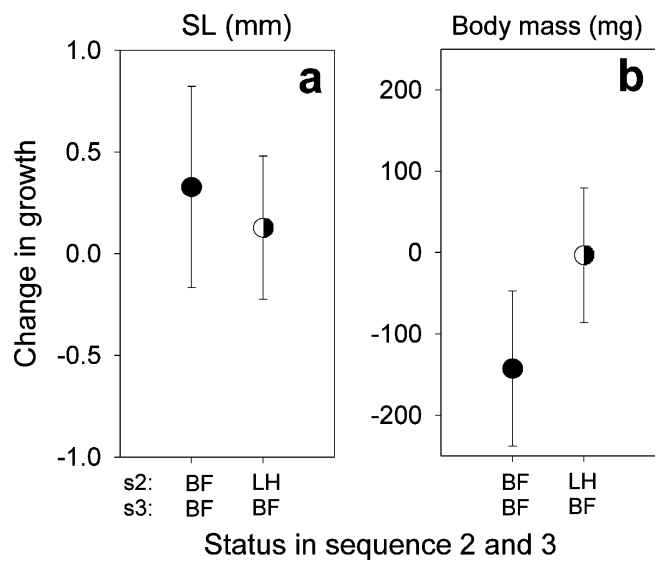

Fig. 3 Status-dependent growth in females. Change in growth rate of females in a standard length SL and b body mass. Compared are breeding females who where breeding female during sequence 2 and 3 $(B F$, black dots, $n=7)$, with large helper females sequence $2(L H)$ who increased in rank to breeder females sequence 3 (white-black dots, $n=27$ ). Depicted are means of growth rate[sequence 3 minus sequence 2] with SEM were very likely to establish an own territory, and reproductive skew between the females was low. Tentatively, one might conclude that in the current experiment, only very small size differences were regarded by the dominant females as immediate threats to their own territory, dominance position and reproduction, as also the results of Heg and Hamilton (2008) suggest. Heg and Hamilton (2008) also found that breeder females actually grow slower when living in groups with one helper female, compared to breeder females without helpers. This may explain the relatively slow accumulation of mass of breeder females.

Field data suggest female $N$. pulcher show distinct size hierarchies (D. Heg, unpublished data), very much like the congener Neolamprologus savoryi (Heg et al. 2005a). These size hierarchies could be due to female strategic growth adjustments when they closely approach the size of their breeder female but may also be due to other processes. The most likely candidates are that large subordinate females acquire part of the group's territory or extend part of this territory for own breeding, before they get evicted from the group by the breeder female (Stiver et al. 2006). As helper females are more likely to acquire a separate breeding territory when they are relatively large (Heg and Hamilton 2008), they may have left the group before they 'need' to show strategic growth adjustments. Note that in this study, helper females could not leave their group but did reproduce (Heg 2008). This would explain the regular occurrence of polygyny in these cichlids, where breeder females may either defend parts of the same patch against each other or defend separate patches (e.g. Limberger 1983; Heg et al. 2005a).

Another candidate explanation is that breeder females grow depending on the size difference with the breeder male (Munday et al. 2006), but this was not supported by the data. Finally, breeder males may interfere in femalefemale conflict to ensure that multiple females get to breed 
Table 2 GEE statistical analysis of strategic growth in female helper cichlids

\begin{tabular}{|c|c|c|c|c|c|c|}
\hline \multirow[t]{2}{*}{ Parameter } & \multicolumn{3}{|c|}{ Growth SL (mm, $n=64)$} & \multicolumn{3}{|c|}{ Growth body mass (mg, $n=64)$} \\
\hline & $\chi^{2}$ & $d f$ & $P$ & $\chi^{2}$ & $d f$ & $P$ \\
\hline Intercept & 1.1 & 1 & 0.29 & 1.5 & 1 & 0.22 \\
\hline $\operatorname{Ln}[\text { initial size }]^{\mathrm{a}}$ & 0.8 & 1 & 0.36 & 2.7 & 1 & 0.1 \\
\hline $\operatorname{Ln}[\text { difference in size }]^{\mathrm{b}}$ & 1.8 & 1 & 0.18 & 0.8 & 1 & 0.36 \\
\hline Sequence & 7.2 & 1 & 0.007 & 18.5 & 1 & $<0.001$ \\
\hline
\end{tabular}

Data for large helper females during sequence 1 and 2. Results corrected for random individual effects

SL standard length

${ }^{a}$ Focal size at the start of the sequence: SL for growth SL and body mass for growth mass, both ln-transformed before analyses

${ }^{\mathrm{b}}$ Difference in size between the breeder female and the large helper female at the start of the sequence, SL for growth SL and body mass for growth mass, ln-transformed before analyses

inside their territory (Schradin and Lamprecht 2000) and to ensure that reproductively capable subordinate females do not leave the territory (e.g. Schradin and Lamprecht 2002, 'third-party effects'). Likewise, it may be in the males interest to increase the growth rate of potential mates inside their group by active interference, particularly because productivity increases with female body size (Heg and Hamilton 2008) and subordinate females do reproduce in the field (Stiver et al. 2009). Theoretical models have shown that third-party effects may have important consequences for group stability (emigration or eviction of subordinates) and reproductive skew (Hamilton and Heg 2007), and similarly, they may affect growth adjustments within groups.

It is interesting to dwell on the differences in growth adjustments found in males (Heg et al. 2004b) and females

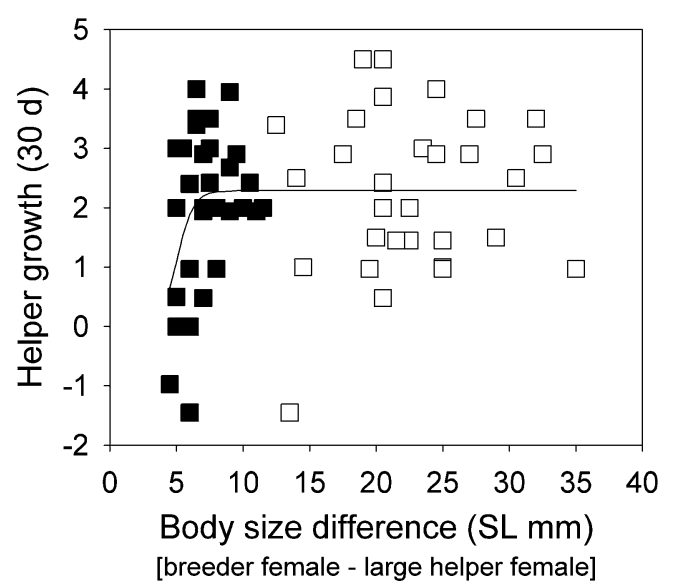

Fig. 4 Strategic growth of large helper females $(n=64)$. Growth rate (SL millimetre) of these females was related to the size difference with their breeder female and showed a nonlinear relationship (line): growth SL millimetre $=a /[1+\exp (b+c \times$ size difference $)], R^{2}=0.10$, with coefficients \pm SE: $a=2.28 \pm 0.20, b=8.41 \pm 8.24, c=-1.66 \pm 1.59$. Black squares, small breeder female treatment; white squares, large breeder female treatment (this study). Breeder males may have more to lose from a competitor helper male than breeder females may have to lose from a competitor helper female (Heg et al. 2006). This is due to breeder males actively competing for fertilizations with their group member males, whereas breeder females may only lose alloparental care from subordinates helping competitor females in raising their broods, instead of their own brood. In practice, however, helper females who do reproduce nevertheless show alloparental care of the breeder female's brood (Heg and Hamilton 2008; Heg et al. 2009). Breeder females only have to ensure that a sufficient number of helpers stay inside their territory and help, particularly since her investment correlates negatively with the investment by her helper (Heg and Hamilton 2008; Heg et al. 2009). Heg and Hamilton (2008) have shown that this is more difficult if the breeding resources are widely spaced, since this will make it more likely that the helper female will monopolise one such resource and breed independently. Polygynous females who defend separate territories do not help each other in raising their broods (Heg and Hamilton 2008) and usually have their own contingent of helpers (see for examples Limberger 1983; Heg et al. 2005a), where only the largest helpers may be shared amongst multiple breeder females (personal observations).

I conclude that conflicts between males inside groups may be resolved by status-dependent and strategic growth adjustments, through the maintenance of a stable, body size-dependent, dominance hierarchy. Conflicts in females may be resolved by similarly sized female group members out-spacing themselves over separate breeding patches within the dominant male's territory (i.e. more breeding patches available induces more polygyny: Limberger 1983; Heg and Hamilton 2008). Only in a situation where this has been prevented (this study), females may show strategic growth adjustments when they closely approach the breeder female in size, and females did not show status-dependent growth. Whether reproductive conflicts may be appeased 
due to adjustments in alloparental care (see Heg et al. 2009) or other behaviours (Bergmüller et al. 2005; Bergmüller and Taborsky 2005; Hamilton et al. 2005) remains to be tested.

Acknowledgement I thank R. Schürch and E. Jutzeler for their help, support and discussions throughout this project. I thank the referees for their comments on the manuscript. This study was supported by SNF Grant 3100A0-108473.

\section{References}

Ali M, Nicieza A, Wootton RJ (2003) Compensatory growth in fishes: a response to growth depression. Fish \& Fisheries 4:147-190

Aubin-Horth N, Desjardins JK, Martei YM, Balshine S, Hofmann HA (2007) Masculinized dominant females in a cooperatively breeding species. Mol Ecol 16:1349-1358

Awata S, Kohda M (2004) Parental roles and the amount of care in a bi-parental substrate brooding cichlid: the effect of size differences within pairs. Behaviour 141:1135-1149

Awata S, Munehara H, Kohda M (2005) Social system and reproduction of helpers in a cooperatively breeding cichlid fish (Julidochromis ornatus) in Lake Tanganyika: field observations and parentage analyses. Behav Ecol Sociobiol 58:506-516

Awata S, Heg D, Munehara H, Kohda M (2006) Testis size depends on social status and the presence of male helpers in the cooperatively breeding cichlid Julidochromis ornatus. Behav Ecol 17:372-379

Balshine-Earn S, Neat FC, Reid H, Taborsky M (1998) Paying to stay or paying to breed? Field evidence for direct benefits of helping behavior in a cooperatively breeding fish. Behav Ecol 9:432-438

Bender N, Heg D, Hamilton IM, Bachar Z, Taborsky M, Oliveira RF (2006) The relationship between social status, behaviour, growth and steroids in male helpers and breeders of a cooperatively breeding cichlid. Horm Behav 50:173-182

Bergmüller R, Taborsky M (2005) Experimental manipulation of helping in a cooperative breeder: helpers 'pay to stay' by preemptive appeasement. Anim Behav 69:19-28

Bergmüller R, Heg D, Taborsky M (2005) Helpers in a cooperatively breeding cichlid stay and pay or disperse and breed, depending on ecological constraints. Proc R Soc London B 272:325-331

Brouwer L, Heg D, Taborsky M (2005) Experimental evidence for helper effects in a cooperatively breeding cichlid. Behav Ecol 16:667-673

Buchner AS, Sloman KA, Balshine S (2004) The physiological effects of social status in the cooperatively breeding cichlid Neolamprologus pulcher. J Fish Biol 65:1080-1095

Buston P (2003) Size and growth modification in clownfish. Nature 424:145-146

Buston P (2004) Does the presence of non-breeders enhance the fitness of breeders? An experimental analysis in the clown anemonefish Amphiprion percula. Behav Ecol Sociobiol 57:23-31

Desjardins JK, Hazelden MR, Van Der Kraak GJ, Balshine S (2006) Male and female cooperatively breeding fish provide support for the "Challenge Hypothesis". Behav Ecol 17:149-154

Desjardins JK, Fitzpatrick JL, Stiver KA, Van Der Kraak GJ, Balshine S (2008a) Costs and benefits of polygyny in the cichlid Neolamprologus pulcher. Anim Behav 75:1771-1779

Desjardins JK, Stiver KA, Fitzpatrick JL, Milligan N, Van Der Kraak GJ, Balshine S (2008b) Sex and status in a cooperative breeding fish: behavior and androgens. Behav Ecol Sociobiol 62:785-794

Dierkes P, Taborsky M, Achmann R (2008) Multiple paternity in the cooperatively breeding fish Neolamprologus pulcher. Behav Ecol Sociobiol 62:1582-1589
Fitzpatrick JL, Desjardins JK, Stiver KA, Montgomerie R, Balshine S (2006) Male reproductive suppression in the cooperatively breeding fish Neolamprologus pulcher. Behav Ecol 17:25-33

Francis RC (1988) Socially mediated variation in growth rate of the midas cichlid: the primacy of early size differences. Anim Behav 36:1844-1845

Fricke H, Fricke S (1977) Monogamy and sex change by aggressive dominance in coral reef fish. Nature 266:830-832

Hamilton IM, Heg D (2007) Clutch-size adjustments and skew models: effects on reproductive partitioning and group stability. Behav Ecol 18:467-476

Hamilton IM, Heg D (2008) Sex differences in the effect of social status on the growth of subordinates in a cooperatively breeding cichlid. J Fish Biol 72:1079-1088

Hamilton IM, Heg D, Bender N (2005) Size differences within a dominance hierarchy influence conflict and help in a cooperatively breeding cichlid. Behaviour 142:1591-1613

Harwood AJ, Armstrong JD, Metcalfe NB, Griffiths SW (2003) Does dominance status correlate with growth in wild stream-dwelling Atlantic salmon (Salmo salar)? Behav Ecol 14:902-908

Heg D (2008) Reproductive suppression in female cooperatively breeding cichlids. Biol Lett 4:606-609

Heg D, Bachar Z (2006) Cooperative breeding in the Lake Tanganyika cichlid Julidochromis ornatus. Environm Biol Fish 76:265-281

Heg D, Hamilton IM (2008) Tug-of-war over reproduction in a cooperatively breeding cichlid. Behav Ecol Sociobiol 62:12491257

Heg D, Bachar Z, Brouwer L, Taborsky M (2004a) Predation risk is an ecological constraint for helper dispersal in a cooperatively breeding cichlid. Proc R Soc London B 271:2367-2374

Heg D, Bender N, Hamilton I (2004b) Strategic growth decisions in helper cichlids. Proc R Soc London B 271:S505-S508

Heg D, Bachar Z, Taborsky M (2005a) Cooperative breeding and group structure in the Lake Tanganyika cichlid Neolamprologus savoryi. Ethology 111:1017-1043

Heg D, Brouwer L, Bachar Z, Taborsky M (2005b) Large group size yields group stability in the cooperatively breeding cichlid Neolamprologus pulcher. Behaviour 142:1615-1641

Heg D, Bergmüller R, Bonfils D, Otti O, Bachar Z, Burri R, Heckel G, Taborsky M (2006) Cichlids do not adjust reproductive skew to the availability of independent breeding options. Behav Ecol 17:419-429

Heg D, Jutzeler E, Bonfils D, Mitchell JS (2008) Group composition affects male reproductive partitioning in a cooperatively breeding cichlid. Mol Ecol 17:4359-4370

Heg D, Jutzeler E, Mitchell JS, Hamilton IM (2009) Helpful female subordinate cichlids are more likely to reproduce. PLoS ONE 4: e5458

Hofmann HA, Benson ME, Fernald RD (1999) Social status regulates growth rate: consequences for life-history strategies. Proc N Acad Sci USA 96:14171-14176

Kohda M, Shibata Y, Awata S, Gomagano D, Takeyama T, Hori M, Heg D (2008) Niche differentiation depends on body size in a cichlid fish: a model system of a community structured according to size regularities. J Anim Ecol 77:859-868

Kohler U (1998) Zur Struktur und Evolution des Sozialsystems von Neolamprologus multifasciatus (Cichlidae, Pisces), dem kleinsten Schneckenbuntbarsch des Tanganjikasees. Shaker Verlag, Aachen

Limberger D (1983) Pairs and harems in a cichlid fish, Lamprologus brichardi. Z Tierpsych 62:115-144

Metcalfe NB, Monaghan P (2003) Growth versus lifespan: perspectives from evolutionary ecology. Exp Gerontol 38:935-940

Mitchell JS (2003) Social correlates of reproductive success in false clown anemonefish: subordinate group members do not pay-tostay. Evol Ecol Res 5:89-104 
Munday PL, Cardoni AM, Syms C (2006) Cooperative growth regulation in coral-dwelling fishes. Biol Lett 2:355-358

Nakagawa S, Cuthill IC (2007) Effect size, confidence interval and statistical significance: a practical guide for biologists. Biol Rev 82:591-605

Norusis MJ (2007) SPSS 15.0 advanced statistical procedures companion. Prentice Hall, Upper Sadle River

Royle NJ, Lindstrom J, Metcalfe NB (2005) A poor start in life negatively affects dominance status in adulthood independent of body size in green swordtails Xiphophorus helleri. Proc R Soc London B 272:1917-1922

Schradin C, Lamprecht J (2000) Female-biased immigration and male peace-keeping in groups of the shell-dwelling cichlid fish Neolamprologus multifasciatus. Behav Ecol Sociobiol 48:236242

Schradin C, Lamprecht J (2002) Causes of female emigration in the group-living cichlid fish Neolamprologus multifasciatus. Ethology 108:237-248

Sloman KA, Gilmour KM, Taylor AC, Metcalfe NB (2000) Physiological effects of dominance hierarchies within groups of brown trout, Salmo trutta, held under simulated natural conditions. Fish Physiol Biochem 22:11-20

Stiver KA, Fitzpatrick J, Desjardins JK, Balshine S (2006) Sex differences in rates of territory joining and inheritance in a cooperatively breeding cichlid fish. Anim Behav 71:449-456

Stiver KA, Fitzpatrick J, Desjardins JK, Balshine S (2009) Mixed parentage in Neolamprologus pulcher groups. J Fish Biol 74:1129-1135

Taborsky M (1984) Broodcare helpers in the cichlid fish Lamprologus brichardi: their costs and benefits. Anim Behav 32:1236-1252

Taborsky M, Limberger D (1981) Helpers in fish. Behav Ecol Sociobiol 8:143-145

Whiteman EA, Cote IM (2004) Dominance hierarchies in group-living cleaning gobies: causes and foraging consequences. Anim Behav 67:239-247

Wong MYL, Buston PM, Munday PL, Jones GP (2007) The threat of punishment enforces peaceful cooperation and stabilizes queues in a coral-reef fish. Proc R Soc London B 274:1093-1099

Wong MYL, Buston PM, Munday PL, Jones GP (2008) Fasting or feasting in a fish social hierarchy. Curr Biol 18:R372-R373 